\title{
Evaluation of mini nutrition assessment (MNA) tool among community dwelling elderly in urban community of Hawassa city, Southern Ethiopia
}

\author{
Hailu Hailemariam ${ }^{1}$, Pragya Singh ${ }^{2^{*}}$ and Tigist Fekadu ${ }^{3}$
}

\begin{abstract}
Background: Mini nutrition assessment (MNA) was found to be the most extensively evaluated method of nutritional assessment for geriatrics settings even if there is no gold standard method to assess nutritional status of elderly. However, MNA has not been validated among Ethiopian elderly. Therefore, the present study examined whether full MNA can identify malnutrition and risk of malnutrition in elderly population living in urban community of Hawassa city, Southern Ethiopia.

Method: Cross-sectional study was conducted among 548 community dwelling elderly ( $\geq 60)$ ('287women' and '261 men'). Simple random sampling method was employed to select eligible elderly after preparing sampling frame. Those with visible deformity of extremities were excluded. MNA tool was administered to 548 elderly. Reliability of the MNA was calculated using coefficient of Cronbach's a and Spearman's rank association between total MNA score \& eighteen items of MNA. Overall accuracy, sensitivity and specificity of the MNA were estimated using ROC curve. Youden index was also used to determine the best cut-off point.

Result: The mean MNA score was $18.95 \pm 3.89$ and there was no significantdifference across gender $\left(19.5 \mathrm{~V}_{\mathrm{s}}\right.$ 18.4; $P>0.05)$. Morethan quarter, 155 (28.3\%) of the elderly were identified as malnourished (MNA: <17) and more than half, 342 (62.4\%) were at risk of malnutrition (MNA: 17-23.5). Cronbach's a coefficient was found 0.65. Besides, a significant correlation was found between total MNA score and all items of the MNA and the participants' self-perceived nutritional status $(\gamma=0.532, P<0.001)$. The area under the curve (AUC) was found to be 0.84 ( $95 \% \mathrm{Cl}$ $0.792-0.887 ; P<0.001)$ indicating overall accuracy of the tool. The sensitivity and specificity of the MNA tool using established cut off point were found 80.1 and $72.5 \%$ respectively. However, using the Youden index the best cut-off point to detect malnourished and at risk of malnutrition was found 15 with sensitivity of $92.1 \%$ \& specificity of $43.5 \%$.

Conclusions: MNA with its established cut-off points may fit for Ethiopian elderly populations even if it needs modulation with the cut-off point. Further exhaustive research is needed to validate the Mini Nutrition Assessment tool using dietary and clinical data.
\end{abstract}

Keywords: Elderly, MNA, Malnutrition, Validity, Reliability, Sensitivity, Specificity

\footnotetext{
*Correspondence: pragyasingh85@yahoo.co.in

${ }^{2}$ Department of Public Health \& Primary Care, Fiji National University, Suva, Fiji

Full list of author information is available at the end of the article
} 


\section{Background}

Aging is coupled with increased risk of malnutrition because of the interaction of various physiological, psychological and socioeconomic factors [1,2]. Malnutrition in elderly is defined as a state of under-nutrition which has resulted from prolonged protein and energy restriction $[2,3]$. If malnutritionis not intervened in its early stage amongelderly population it can result in various negative health outcomessuch as morbidity, poor quality of life and impaired functional autonomy $[4,5]$.

Assessment of the nutritional status among elderly includes both biochemical and anthropometric measurements. However; using these two measurements together to assess nutritional status of a large number of elderly is not feasible [6]. Therefore, for a long time single anthropometric measurements were used to assess the nutritional status of elderly $[7,8]$ even if they failed to provide adequate estimates of nutritional status of elderly people [9].

However, now a number of nutritional assessment instruments including the Mini Nutritional Assessment (MNA) have been developed to assess nutritional status of elderly [10]. The MNA tool, which was published in 1994, is a short, non-invasive, reliable and extensively evaluated nutritional assessment tool for free-living and clinically relevant elderly populations $[10,11,12]$.

MNA exhibits good sensitivity and specificity compared to a variety of nutritional assessment parameters including biochemical values, anthropometric values and dietary intakes [13]. MNA tool is likewise suggested by the European Society for Clinical Nutrition and Metabolism (ESPEN) for routine geriatric nutritional assessments [14]. Mini Nutrition Assessment (MNA) tool contains geriatric-related assessment questions specific to nutritional and health conditions, autonomy, quality of life, cognition, mobility and personal health [15]. Full MNA is composed of 18 questions which are divided in to four main categories; dietary assessment, subjective assessment, global assessment and anthropometric data. MNA gives a maximum of 30 points and it classifies the elderly in: malnourished (MNA $<17$ points), at risk of malnutrition (MNA: 17-23.5) and well nourished (MNA $>=24$ points) $[12,16]$. However, these cut off points may not be applicable for elderly population living in different countries around the world because populations living in different parts of the world are heterogeneous in nutritional characteristics. For instance, MNA had failed to categorize at risk for malnutrition among Chilean elderly populations [17]. MNA has not been validated in Ethiopian elderly population. Therefore, the present study was conducted with the objective to evaluate whether MNA can identify malnutrition and risk for malnutrition among elderly population living in urban community of Hawassa city, Southern Ethiopia.

\section{Methods}

The study was conducted in Hawassa city from 28th April to 21th June, 2012. A descriptive, cross-sectional study design was employed among 548 community dwelling elderly. Simple random sampling method was employed to select eligible elderly after preparing sampling frame prior to the study. Age ( $\geq 60$ years), informed writtenconsent, living for more than six months in study area and ability to communicate during the interview were considered as inclusion criteria. All elderly people ( $\geq 60$ years) who were having visible deformity of upper or lower extremities were excluded from the study. Ethical clearance was taken from Hawassa University, Health Science College ethical review board.

\section{Assessment of nutritional status}

Mini Nutrition Assessment (MNA) was administered to five hundred forty eight eligible elderly after validation of the tool. The tool was validated against BMI. BMI was used for validation instead of dietary intake or clinical data because there existsrecall bias in case of dietary data and limitation of getting high quality and full clinical data.

All interviews from MNA tool regarding the nutritional and health conditions, functional independence, quality oflife, mobility, cognition and subjective health were assessed by trained nurses as per the standard stated in the original MNA tool [12]. As a component of the full MNA, all anthropometric measurements (weight, height, mid upper arm circumference and calf circumference) were measured on the non-dominant arm and leg. Weight was recorded to the closest $0.1 \mathrm{~kg}$ with the subject in light dress and shoeless utilizing an electronic weight scale adjusted with $1 \mathrm{~kg}$ standard weights after every estimation. Height was recorded to the closest $0.1 \mathrm{~cm}$ utilizing a stadiometer after the subject standing erect and looking straight ahead with heels, buttocks and shoulders pressed against the stadiometer. Demispan measurement was used by quantifying the distance from the midline at the sternal notch to the web between the middle and ring fingers along outstretched arm whenever participants were unable to stand on the stadiometer. Height is then calculated using a standard formula (females height in $\mathrm{cm}=(1.35 \times$ demispan in $\mathrm{cm})+60.1$ and males height in $\mathrm{cm}=(1.40 \times$ demispan in cm) + 57.8) [18]. Mid Upper Arm Circumference (MUAC) was measured to the nearest $0.1 \mathrm{~cm}$ at the mid-point between the tip of the acromion and the olecranon process on the back of the arm while the subject holding the forearm in horizontal position. The measurement was performed on the subject's arm hanging freely along the trunk using inextensible MUAC tape. The widest calf circumference was measured between the ankle and knee to the nearest $0.1 \mathrm{~cm}$ using non stretchable tape 
in a sitting position with the leg bent $90^{\circ}$ at the knee and manipulated to maintain close contact with the skin without compression of underlying tissues. Body Mass Index (BMI) was calculated as body weight in kilograms divided by the square of height in meter.

\section{Statistical analysis and interpretation}

All analysis was performed using SPSS statistical software package version 16.0. One sample Kolmogorov Smirnov test was used to check the distribution of continuous variables. Descriptive frequencies were used to look for overall distribution of the study subject with the variables under study.

Reliability of the MNA wascalculated using coefficient of Cronbach's $\alpha$ and a Cronbach's $\alpha$ value of $0.60,0.70$ \& 0.80 were considered acceptable, adequate and good respectively [19]. Moreover, the internal consistency (reliability) of the MNA tool was evaluated after checking Spearman's rank association between total MNA score and every items of the MNA after omitting each item in every correlation [20].

Criterion-related validity of the MNA tool was evaluated after checking a significant positive Spearman's rank association between total MNA score and single anthropometric measurements. Besides, the concurrent validity of the tool was checked after identifying a significant positive Spearman's rank correlation between total MNA score and self-perceived nutritional status [21]. Spearman's rank correlation was also used to correlate categorical BMI as in the MNA tool and total MNA score while Pearson's correlation was used to check correlation between total MNA score and the continuous variable BMI.
Finally, the construct validity of the MNA tool to identify malnutrition and at risk for malnutrition in the elderly population was assessed using receiveroperating characteristic (ROC) curve which computes the sensitivity \& 1 - specificity of the tool using BMI < $18.5 \mathrm{~kg} / \mathrm{m}^{2}$ as a marker of malnutrition [21]. The area under the ROC curve (AUC) was evaluated to determine overall accuracy of the MNA and a bigger AUC symbolizes a better reliability. Youden index (Sensitivity + specificity _ 1) was used to conclude the best cutoff point of MNA [22].

\section{Results}

Full MNA was administered to 548 elderly (287 and 261 men). The mean age was $68.97 \pm 6.97$ years. The nutritional status estimated by MNA tool in the current study was found to be deteriorating for both sexes as the age of the elderly advanced $(\gamma=-0.208, P<0.001)$ (Fig. 1 ).

The mean MNA score was $18.95 \pm 3.89$ and the mean was not significantly different for men and women $(19.5$ $\mathrm{V}_{\mathrm{s}} 1$ 18.4; $\left.P>0.05\right)$. Moreover, more than quarter, 155 $(28.3 \%)$ of the elderly were identified as malnourished (MNA: <17), more than half, $342(62.4 \%)$ were at risk of malnutrition (MNA: 17-23.5) and only, 51 (9.3\%) of the elderly were classified as having an adequate nutritional status (MNA: 24-30).

\section{Characteristics of Mini Nutrition Assessment (MNA) tool Reliability of MNA tool}

The internal consistency as measured by coefficient Cronbach $\alpha$ was found 0.65 . Moreover, a significant positive correlation was found between total MNA score and the

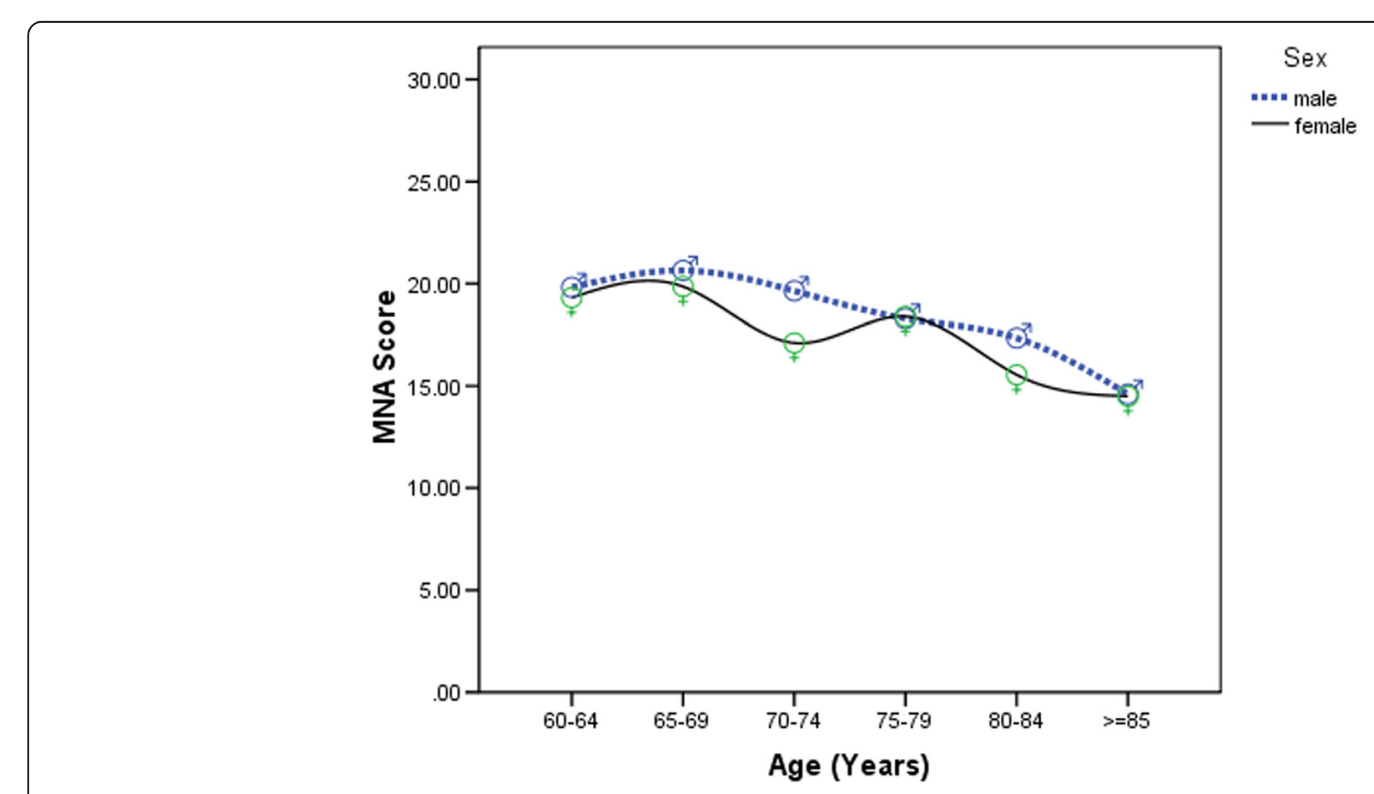

Fig. 1 Trend of Nutritional Status among Elderly Living in Hawassa City by Age and Gender, $2012(n=548)$ 
eighteen items of MNA as a test for reliability of the MNA tool (Table 1).

\section{Validity of MNA tool}

Concurrent and criterion validity A significant positive correlation was observed between total MNA scores and the participants' self perceived nutritional status $(\gamma=0.532, P<0.001)$ as a test for concurrent validity. Besides, a significant positive correlation was found between total MNA score and singleanthropometric measurements demonstrating the criterion validity of MNA tool (Table 2).

Concurrent validity The area under the curve (AUC) was found to be 0.84 (95\% CI $0.792-0.887 ; P<0.001$ ) indicating overall accuracy of the MNA tool to identify malnourished elderly people (Fig. 2). According to the established cut off points, the sensitivity and specificity of the MNA tool to identify malnutrition and risk of malnutrition among the elderly people were found 80.1 and $72.5 \%$ respectively. However, using the Youden index the best cut-off point for MNA to identify malnutrition in the present study area was 15 with sensitivity of $92.1 \%$ and specificity of $43.5 \%$.

Table 1 Correlation between total MNA score and eighteen items of MNA among elderly living in Hawassa City, 2012 $(n=548)$

\begin{tabular}{lll}
\hline MNA variable & $Y$ & $P$ \\
\hline Changes in dietary intake in past 3 months & 0.532 & $<0.001$ \\
Weight loss in past 3 months & 0.616 & $<0.001$ \\
Mobility & 0.373 & $<0.001$ \\
Psychological stress or acute disease in past 3 months & 0.630 & $<0.001$ \\
Dementia & 0.238 & $<0.001$ \\
BMl & 0.621 & $<0.001$ \\
Lives independently & 0.101 & 0.018 \\
More than 3 prescription drugs per day & 0.201 & $<0.001$ \\
Pressure sores & 0.170 & $<0.001$ \\
Number of full meals per day & 0.454 & $<0.001$ \\
Protein intake & 0.234 & $<0.001$ \\
Fruits or vegetables intake & 0.262 & $<0.001$ \\
Fluid intake & 0.206 & $<0.001$ \\
Mode of feeding & 0.106 & 0.013 \\
Self-perceived nutritional status & 0.532 & $<0.001$ \\
Self-perceived health status & 0.317 & $<0.001$ \\
Mid-arm circumference & 0.368 & $<0.001$ \\
Calf circumference & 0.165 & $<0.001$ \\
\hline
\end{tabular}

MNA, Mini Nutrition Assessment; BMI Body Mass Index; $ү$ : Spearman rank correlation coefficient; $P<0.05$ : is significant
Table 2 Correlationbetween MNA and independent anthropometric measurements of elderly living in Hawassa city, $2012(n=548)$

\begin{tabular}{lll}
\hline Variable & Coefficients & $P$ \\
\hline MNA V & & \\
MUAC & $0.408^{\mathrm{b}}$ & $<0.001$ \\
Weight & $0.590^{\mathrm{a}}$ & $<0.001$ \\
Calf circumference & $0.433^{\mathrm{a}}$ & 0.002 \\
BMl & $0.592^{\mathrm{b}}$ & $<0.001$
\end{tabular}

MNA Mini Nutrition Assessment; MUAC Mid Upper Arm Circumference; BM Body Mass Index

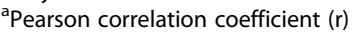

${ }^{\text {bSpearman's rho }(\gamma)}$

\section{Discussion}

Even though there is no gold standard for evaluating nutritional status of the elderly [23], MNA tool has been increasingly engaged worldwide for estimation of older people's nutritional status [12]. In the current study the MNA tool has been tested for its reliability, validity and overall accuracy. The intra-class correlation or value of Cronbach's $\alpha$ was found 0.65 which suggested that the tool has acceptable reliability to identify malnourished elderly [19]. Additionally, a significant positive correlation was found between all items of the tool and the total MNA score which strengthen the internal consistency of the tool. Similar significant correlation was observed between all items of MNA and the total MNA score from a study conducted in Iran [24].

Due to the lack of a gold standard reference for nutritional assessment, the specificity and sensitivity of the

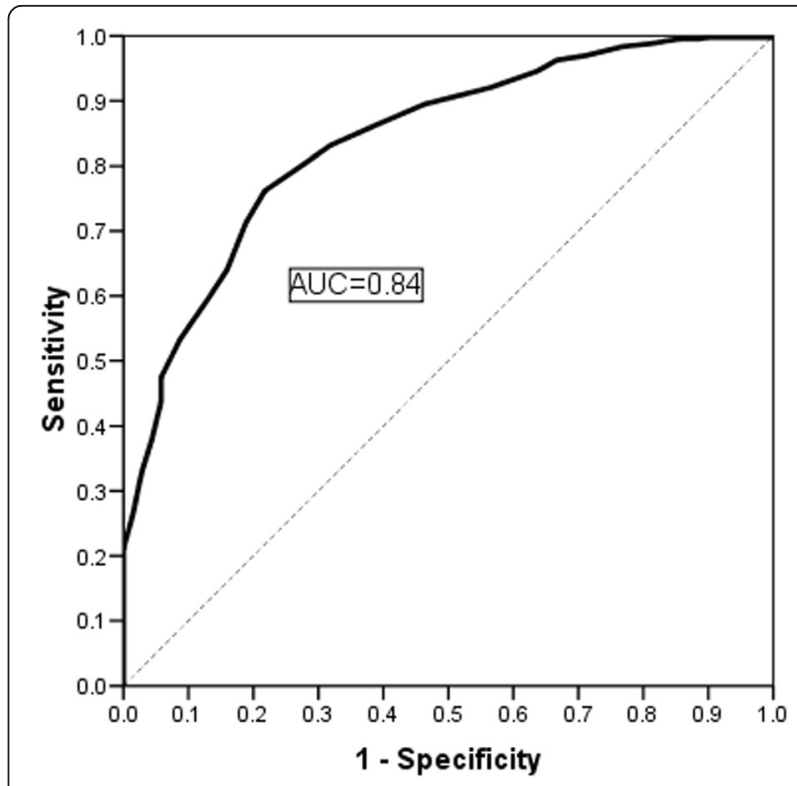

Fig. 2 ROC curve of MNA in predicting lower BMI $\left(<18.5 \mathrm{~kg} / \mathrm{m}^{2}\right)$ as a marker of malnutrition among elderly living in Hawassa city, 2012( $n=548)$ 
MNA tool to identify malnourished elderly showed a wider variation. Therefore, the referee for validating the MNA tool may range from simple anthropometry to a comprehensive nutritional assessment [12].

Guigoz [12] reviewed different studies conducted among 30,000 elderly in different settings around the world and he concluded that the sensitivity and specificity of the MNA tool may range from $41-100 \%$ and 13-98 \% respectively. In the current study using the established cut-off points of MNA, the tool was found to have relatively good sensitivity $(80.1 \%)$ and specificity $(72.5 \%)$ to identify malnutrition and risk of malnutrition. The sensitivity and specificity of the MNA according to its established cut-off points were found 82 and $63 \%$ respectively among Iranian elderly [24].

However, in the current study lowering the cutoff point to 15 has resulted in a substantialenhance in sensitivity by $12 \%$ even if decreased specificity. Thus, this adjustment of the cutoff point will increase the number of true positives (malnourished elderly). Therefore, more elderly would have a higher chance to be included in nutrition intervention programs even if there is a question of cost effectiveness. Besides, higher sensitivity is found to be very important for assessment and screening tools [22].

The current study also revealed that the MNA has relatively good accuracy (84\%) to identify malnutrition and risk of malnutrition among community dwelling elderly. MNA with its established cut off point was found to have 85 and $74 \%$ accuracy in a study from Iran and Japan $[24,25]$.

Increased age is associated to vulnerability for malnutrition among the elderly in the current study. Consistent finding was found from other studies [26, 27] where, nutritional status was found to be deteriorating as age is advancing. This fact of positive correlation between age and nutritional status among elderly seems to be an irreversible phenomenon which is related to degenerative processes. However, the economic, social and cultural aspects should be the goals of policies and programs [28].

\section{Conclusion}

The current study demonstrated that the original full MNA is a reliable and valid nutrition assessment method for identifying malnutrition and at risk of malnutrition among community dwelling elderly in southern Ethiopia. However, this cross-sectional study does not explain the cost effectiveness of the tool and using BMI could be considered as a limitation. Therefore, a prospective study is recommended to evaluate the tool and cost effectiveness of MNA in the prevention, identification and treatment of malnutrition.

\section{Competing interests}

The authors declared no competing interests.

\section{Authors' contributions}

$\mathrm{HH}$ carried out the study design, data management and analysis, and drafted and revised the manuscript. PS participated in the designing of the study, coordinated data collection and data entry; participated in revising and commenting on the draft manuscript. TF participated in designing of the study, and commenting on the draft manuscript. All authors contributed to the interpretation of results and approved the final manuscript.

\section{Acknowledgment}

The authors gratefully acknowledge the expert assistance and financial support of Prof. Barbara Stocker. The authors arethankful to NoRAD project and Arbaminch College of Health Science for their financial and logistic support.

\section{Author details}

${ }^{1}$ Arba Minch College of Health Science, Arbaminch, SNNPR, Ethiopia. ${ }^{2}$ Department of Public Health \& Primary Care, Fiji National University, Suva, Fiji. ${ }^{3}$ Hawassa University, School of Nutrition, Food Science and Technology, Hawassa, SNNPR, Ethiopia.

Received: 22 March 2015 Accepted: 2 February 2016

Published online: 09 February 2016

\section{References}

1. Ahmed T, Haboubi N. Assessment and management of nutrition in older people and its importance to health. Clin Interv Aging. 2010;5:207-16

2. Chen CC, Schilling LS, Lyder CH. A concept analysis of malnutrition in the elderly. J Adv Nursing. 2001:36(1):131-42.

3. Hickson M. Malnutrition and ageing. J Postgrad Med. 2006;2:2-8.

4. Dylan $\mathrm{H}$, Nadim H. Malnutrition screening in the elderly Population. J Royal Soc Med. 2005;98(9):411-4

5. Visvanathan R, Newbury JW, Chapman I. Malnutrition in older people-screening and management strategies. Aust Fam Physician. 2004;33(10):799-805.

6. Reynish W, Vellas B. Nutritional assessment: a simple step forward. Age Ageing. 2001;30:115-61.

7. Cowan DT, Roberts JD, Fitzpatrick JM, While AE, Baldwin J. Nutritional status of older people in long term care settings: current status and future directions. Int J Nurs Stud. 2004:41:225-37.

8. Sieber CC. Nutritional screening tools - how does the MNA compare? J Nutr Health Aging. 2006;6(10):488-92.

9. WHO (world health organization). Physical Status: The Use and Interpretation of Anthropometry. Geneva: WHO; 1995.

10. Cook Z, Kirk S, Lawrenson S, Sandford S. Use of BMI in the assessment of under-nutrition in older subjects: reflecting on practice. Proc Nutr Soc. 2005;64:313-7.

11. Green SM, Watson R. Nutritional screening and assessment tools for older adults: literature review. J Adv Nurs. 2006:54:477-90.

12. Guigoz Y. The Mini nutritional assessment (MNA) review of the literature what does it tell us? J Nutr Health Aging. 2006;10(6):466-87.

13. Bleda MJ, Bolibar I, Pares R, Salva A. Reliability of the mini nutritional assessment (MNA) in institutionalized elderly people. J Nutr Health Aging. 2002;6:13407

14. Kondrup J, Allison SP, Elia M, Vellas B, Plauth M. Educational and Clinical Practice Committee, European Society of Parenteral and Enteral Nutrition (ESPEN). ESPEN guidelines for nutrition screening. Clin Nutr. 2003;22(4):415-21.

15. Bauer JM, Kaiser MJ, Anthony P, Guigoz Y, Sieber CC. The Mini Nutritional Assessment-its history, today's practice, and future perspectives. Nutr Clin Pract. 2008:23(4):388-96.

16. Vellas B, Villars H, Abellan G, Soto ME, Rolland Y, Guigoz Y, et al. Overview of the MNA - its history and challenges. J Nutr Health Aging. 2006;10(6):463-5.

17. Urteaga CR, Ramos RIH, Atalah ES. Validacion del criterio de evaluacionnutrioional global deladulto mayor. Rev Med Chil. 2001;129:871-6

18. Hickson M, Frost GA. Comparison of three methods for estimating height in the acutely ill elderly population. J Hum Nutr Diet. 2003;6:1-3. 
19. Garson G. Validity. Statnotes: Topics in Multivariate Analysis. Available from: http://faculty.chass.ncsu.edu/garson/pa765/statnote.htm. [Accesed on $4^{\text {th }}$ april 2012].

20. Polit DF, Beck CT. Nursing Research: Principles and Methods. 7th ed. Philadelphia: Lippincott Williams and Wilkins; 2004.

21. Streiner DL, Norman GR. Health measurement scales. a practical guide to their development and use. 3rd ed. Oxford: Oxford University Press; 2003.

22. Youden WJ. Index for rating diagnostic test. Cancer. 1950;3:320-35.

23. Jeejeebhoy KN. Nutritional assessment. J Nutr. 2000;16:585-90.

24. Bahareh A, Farshad S, Hossein F, Mojde M, Maryam G, Bagher L. Evaluation of the Mini Nutritional Assessment in the elderly, Tehran, Iran. Public Health Nutr. 2009;13(9):1373-9.

25. Kuzuya M, Kanda S, Koike T, Suzuki Y, Satake S, lquchi A. Evaluation of MiniNutritional Assessment for Japanese frail elderly. Nutrition. 2005;21:498-503.

26. Oyunkhand R, Byambasuren E, Batsereedene B, Chimedsuren O,

Byambasuren S. Nutritional status of Mongolian elderly. Asian J Gerontol Geriatr. 2011;6:42-6.

27. Delacorte RR, Moriguti JC, Matos FD, Marchini JS, Ferriolli E. MNA and the risk for under nutrition in free living older persons. J Nutr Health Aging. 2004;8(6):531-4.

28. Coqueiro RS, Barbosa AR, Borgatto AF. Nutritional status, health conditions and socio-demographic factors inthe elderly of Havana Cuba: data from SABE Survey. J Nutr Health Aging. 2010;14:803-8.

\section{Submit your next manuscript to BioMed Central and we will help you at every step:}

- We accept pre-submission inquiries

- Our selector tool helps you to find the most relevant journal

- We provide round the clock customer support

- Convenient online submission

- Thorough peer review

- Inclusion in PubMed and all major indexing services

- Maximum visibility for your research

Submit your manuscript at www.biomedcentral.com/submit

) Biomed Central 